\title{
Changes at the periphery of a lesion in necrotising scleritis: anterior segment fluorescein angiography correlated with electron microscopy
}

\author{
PETER G WATSON' AND ROBERT D YOUNG ${ }^{2}$ \\ From the 'Department of Ophthalmology, Addenbrooke's Hospital, Cambridge and the Scleritis Clinic, \\ Moorfields Eye Hospital, London, and ${ }^{2}$ Strangeways Research Laboratory, Cambridge
}

SUMmARY Anterior segment fluorescein angiography in scleral disease reveals highly characteristic changes in the vasculature of the anterior segment associated with necrotising scleritis. The vaso-obliterative changes discovered in this investigation have been correlated with the histopathology in a patient who had to have tissue replaced. Light and electron microscopy of scleral tissue excised from sites of vascular closure detected by fluorescein angiography peripheral to the scleral defect revealed pathological changes in the absence of inflammatory cell infiltration. These changes included vascular stasis, partial vaso-obliteration, and fibroblastic transformation of scleral fibrocytes in association with intra- and extracellular degradation of the collagenous component of the matrix.

A wide spectrum of inflammatory conditions can be recognised which affect the connective tissue coats of the eye, but not all give rise to destruction of the scleral matrix. ${ }^{2}$ Clinically the inflammatory changes may be confined to the episcleral tissue alone (episcleritis) or involve the deeper scleral tissue (scleritis). The inflammation usually affects the anterior segment, but if it does extend or arise behind the equator a posterior scleritis may develop. The most serious form of scleral inflammation is necrotising scleritis in which the sclera is destroyed by the inflammatory process or becomes sequestered and later removed.

Recent studies have shown the value of anterior segment fluorescein angiography in the early detection of necrotising scleritis. ${ }^{23}$ In episcleritis and in diffuse and nodular scleritis which do not give rise to destructive changes the vascular flow is rapid and the vessels readily perfused. In necrotising scleritis, however, the vascular flow is markedly reduced. If the condition persists the vessels become nonperfused. Once this has occurred reperfusion of these vessels does not take place even though the inflammation resolves. In some patients the sclera in the area of non-perfusion will necrose, ulcerate, or

Correspondence to Mr P G Watson, FRCS, 17 Adams Road, Cambridge. sequestrate. Vascular changes can be detected remote from but contiguous with those areas of scleral destruction. The purpose of this investigation was to identify the changes in the sclera which occur within those areas.

\section{Material and methods}

\section{PHOTOGRAPHY}

Colour photographs of the lesions were taken at a magnification of $10 \times$ and $16 \times$ on a Zeiss photo slit lamp with Ektachrome 64 ASA film and a diffuse light source. A camera aperture between $\mathrm{f} 22$ and $\mathrm{f} 32$ was selected depending on the amount of reflected light from the sclera.

\section{FLUORESCEIN ANGIOGRAPHY}

This was performed on the same camera using a power pack with a recycling time of one second at full output. A Zeiss blue glass filter 30:14:63 (465 nm) was placed in front of the flash source and an interferential barrier filter of $525 \mathrm{~nm}$ of sharp cut-off characteristics placed in front of the film. The film used was 400 ASA Ilford HP5 or Kodak Tri X developed in ID11 for 12 minutes at $68^{\circ} \mathrm{F}\left(20^{\circ} \mathrm{C}\right)$.

With the patient positioned on the slit lamp, two control photographs were taken at $10 \times$ or $16 \times$ before injection of dye in order to determine the 
degree of autofluorescence. Autofluorescence was minimised by adjusting either the angle of incident illumination or the intensity of the flash. The angiographic series was undertaken in darkness to exclude pseudofluorescence.

$5 \mathrm{ml}$ of $10 \%$ fluorescein was injected into the antecubital vein. Photographs were taken at onesecond intervals beginning 10 seconds after the time of the injection, because almost all the relevant information is obtained from the very early passage of dye through the anterior segment vessels. A few photographs were also taken in the late venous phase. A yellow barrier filter routinely used over the eyepiece was omitted to facilitate observations of the very earliest dye transit. Care was exercised in precise focusing and exact alignment perpendicular to the point of interest, because of the very small depth of field available.

Late phase photographs were taken in areas remote from the site of inflammation to compare the late staining characteristics.

The results were evaluated from positive transparent contact prints.

\section{MICROSCOPY}

Tissue from the site of examination by fluorescein angiography, removed intact during the preparation of the graft bed in each of the two scleral lamellar grafts, was fixed by immersion for 2 hours at room temperature in $2.5 \%$ glutaraldehyde buffered to pH 7.2 with $0.1 \mathrm{M}$ sodium cacodylate containing $3 \mathrm{mM} \mathrm{CaCl}_{2}$. It was rinsed in buffer, postfixed in $1 \%$ osmium tetroxide, stained en bloc in uranyl acetate, dehydrated, and embedded in Araldite.

Sections approximately $1 \mu \mathrm{m}$ thick were stained in $1 \%$ toluidine blue for light microscopy. Ultrathin sections with silver-gold interference colours, after staining in uranyl acetate and lead citrate, were examined in a Philips $201 \mathrm{C}$ electron microscope.

\section{Results}

\section{CASE HISTORY}

In 1976 at the age of 52 a white male agricultural worker developed rheumatoid arthritis of rapid onset. The disease progressed aggressively in spite of therapy with gold, penicillamine, azathioprine, and non-steroidal inflammatory drugs. Unfortunately he developed severe reactions to each of these drugs, and they had to be withdrawn. In 1979 the left eye became very inflamed but was not very painful. Initially there was a good response to systemic steroid, but then in December 1980 both the sclera and cornea started to ulcerate (Fig. 1). This proceeded in spite of continued high dosage steroid therapy. Laboratory investigations revealed high levels of IgG and IgM, positive results for rheumatoid factor, $1 / 25$ antinuclear factor, and $44 \%$ immune complexes (polyethylene glycol method), and an erythrocyte sedimentation rate of $53 \mathrm{~mm}$ in the first hour.

Because of the progression of the lesion and his failure to respond to therapy at doses which he could tolerate, it was decided to replace the damaged tissues. At operation on 10 February 1981 a lamellar corneoscleral graft together with overlying conjunctiva was performed to include both the ulcerated area and the areas which failed to perfuse on the angiogram (Figs. 2 and 3). It was found that the conjunctiva was adherent to the episclera at this site. Tissue removed in preparation of the graft bed was processed for microscopy. The graft was covered in part with conjunctiva from the contralateral eye, in part with a conjunctival flap, and in part with lyophilised conjunctiva.

Except for some retraction of conjunctiva over the graft the postoperative course was uneventful, and he required no further ocular medication. Because the scleral spur had been removed, the anterior chamber

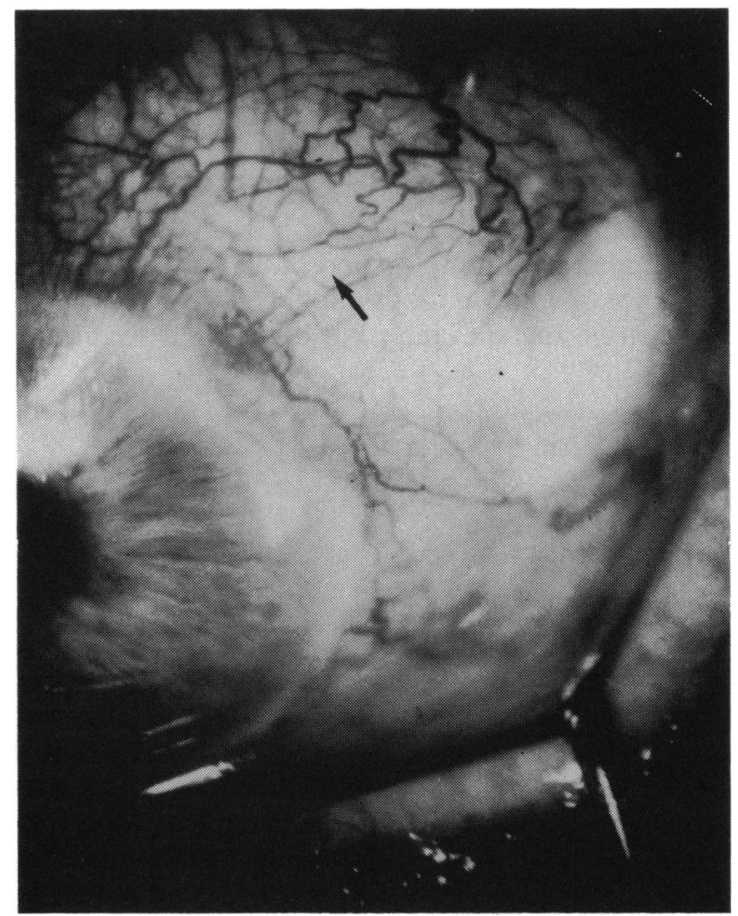

Fig. 1 Necrotising sclerokeratitis. The sclera and overlying conjunctiva are necrotic but there is no surrounding severe inflammatory reaction. The cornea in the same area is infiltrated, with some peripheral corneal tissue loss. Anterior segment fluorescein angiography was performed in the area indicated (arrow). 


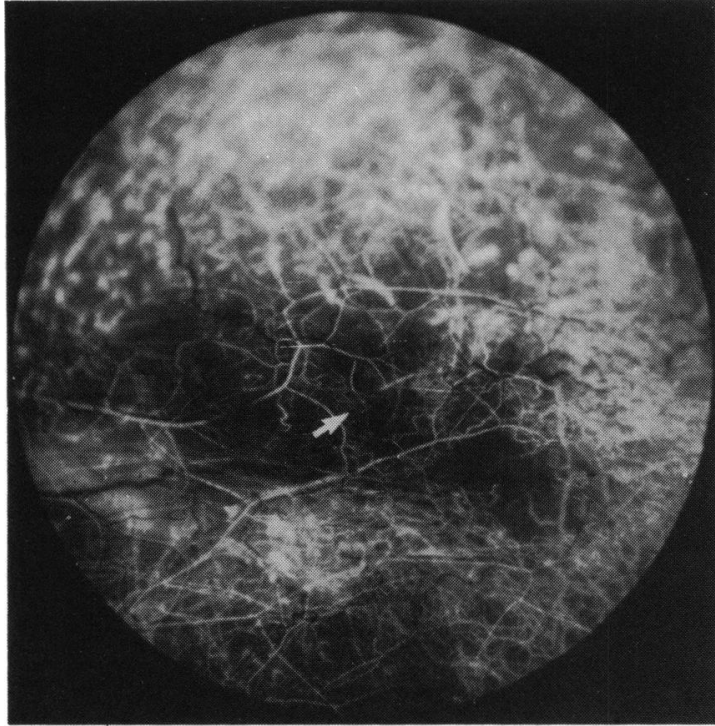

Fig. 2 Anterior segment fluorescein angiogram of area shown in Fig. 1. In the late arterial phase the conjunctival and episcleral vessels in this area are not perfused. The large deep vessels which appear to contain blood have little or no flow in them. Early new vessel capillary loops are seen in the superficial tissue over the area of non-perfusion (arrow).

extended under the lamellar graft for several months (Fig. 4).

Six months later ulceration was noted at the lower end of the graft associated with an active scleritis. Fluorescein angiography subsequently confirmed the presence of vascular loops into the graft, which could be seen on the slit lamp, but also revealed another

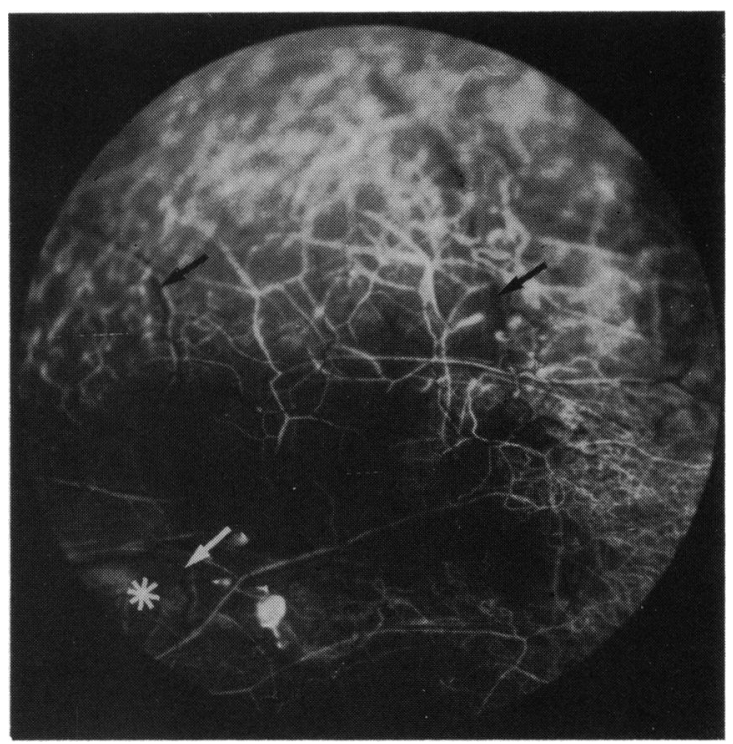

Fig. 3 Later venous phase of same angiogram as in Fig. 2. The capillary network of the conjunctiva is fully perfused above, but both the conjunctival and episcleral vessels have failed to fill below, and this area remained non-perfused throughout the angiogram. The three large vessels (arrows) can be seen adjacent to the arrow in Fig. 1, but these vessels failed to fill with fluorescein even very late in the series. Some deep leakage is occurring below these vessels (asterisk).

region of non-perfusion of deep vessels adjacent to the ulceration (see below). A second lamellar corneoscleral graft was performed on 30 June 1981, during which it was again found that the sclera underlying the area of non-perfusion was abnormal.
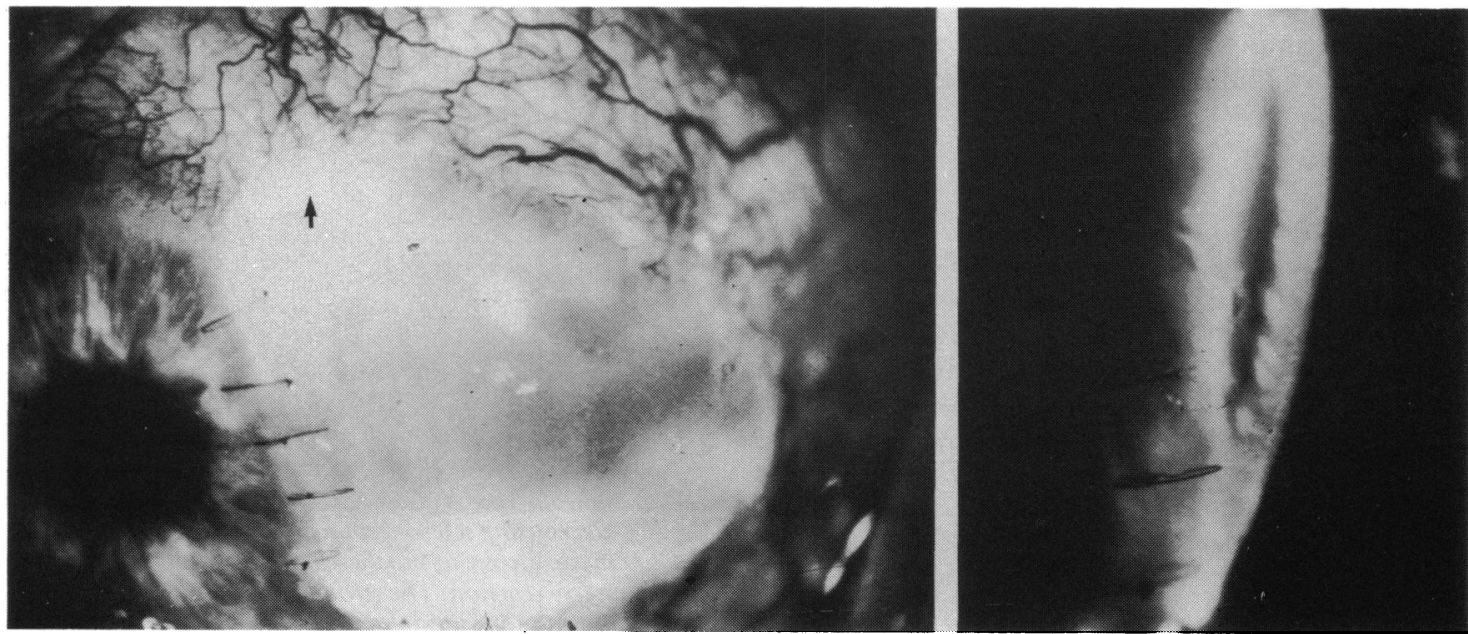

Fig. 4 The appearance after the first graft. The histological material was obtained from the site indicated (arrow). The slit photograph shows the extension of the anterior chamber under the graft. 


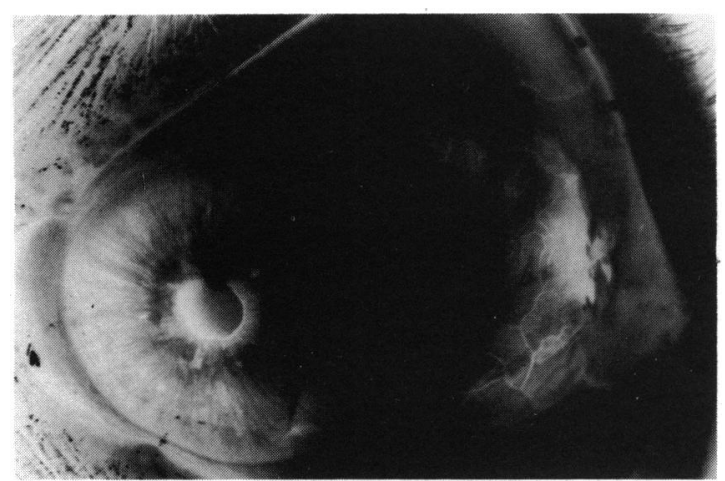

Fig. 5 The appearance two years after the original episode. The grafted tissue has resorbed, leaving a transparent clear graft with absorption of the previously damaged sclera. This has been replaced by semitransparent scar tissue. The cornea has remained healed.

Accordingly the excision was extended in order to replace this abnormal tissue. Three months later he had a myocardial infarction, and on admission to hospital he was found to have a small area of ulceration at the lower end of the second graft, which healed promptly with increased systemic steroid therapy.

Since then, although he has developed a cataract, the eye has remained quiet without inflammation. He has been. maintained on $7.5 \mathrm{mg}$ prednisolone to control his rheumatoid arthritis. The grafted cornea has remained clear, but the adjacent sclera has been gradually resorbed, leaving a thin transparent scar (Fig. 5).
ANTERIOR SEGMENT FLUORESCEIN

ANGIOGRAPHY

Anterior segment fluorescein angiography was performed on 23 January 1981 (Figs. 2 and 3) at the site arrowed in Fig. 1 which was well away from the ulcerated area and adjacent to the edge of the infiltrated cornea.

Angiography revealed a rapid, normal conjunctival vascular filling but this had a well defined limit as the ulcer was approached. In the lower part of the angiogram both the conjunctival and episcleral vessels were either non-perfused or irregularly perfused. The major vessels, although clearly seen (Fig. 1) and presumably containing blood, did not show any fluorescence throughout the angiogram. The capillary loops in the hypoperfused cornea were irregular and abnormal, with evidence of new vessel formation indicative of chronic hypoxia. Deep leakage into the sclera was present underneath the episcleral vessels, arising from vessels in the region of the angle and ciliary body or from new vessels within the sclera.

Further anterior segment fluorescein angiography was performed at the lower end of the graft when the scleritis reactivated and the graft tissue began to ulcerate (20 June 1981). This showed active new vessel loops extending into both graft and normal cornea. There was also a large vascular tuft extending round the limbus below the graft. The vessels adjacent to the graft, however, were non-perfused (Fig. 6, arrow).

\section{MICROSCOPY}

No major accumulation of inflammatory cells com-

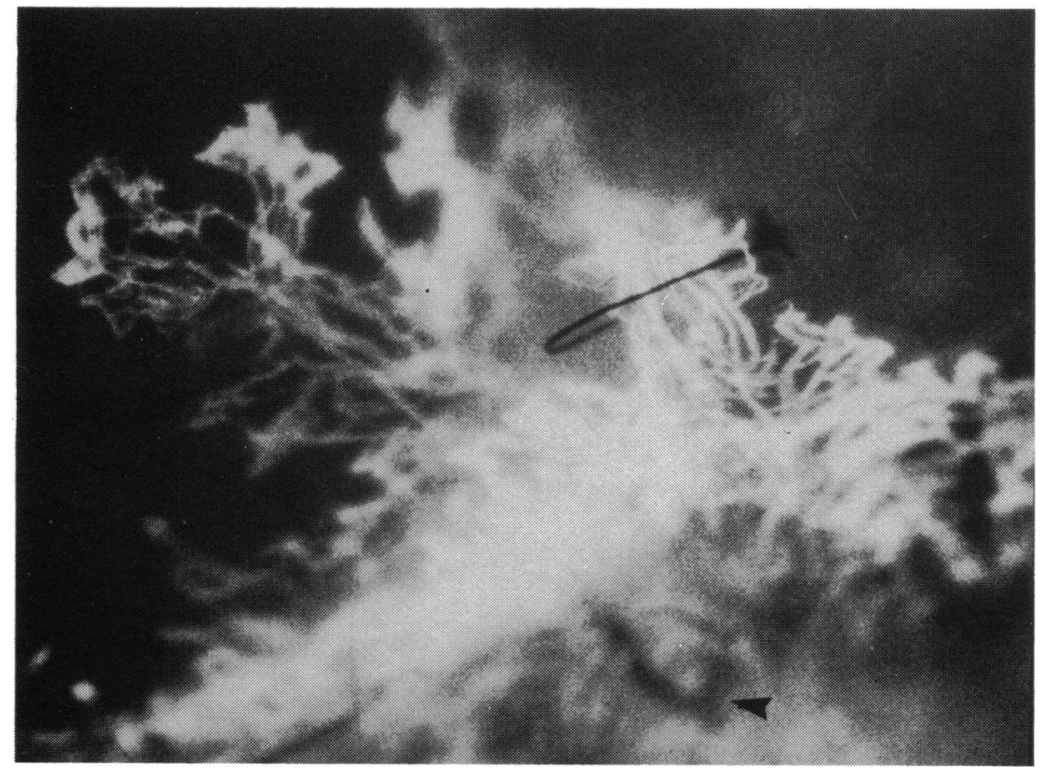

Fig. 6 New vessel loops entering the graft at the site of the recurrence of the destructive process. The vessels below the graft are not perfused (arrowhead). 
Fig. 7 Patent vessels at the site of the angiogram, at the ulcer periphery. Although the vessels appear patent, the red blood cells are densely packed, suggesting sluggish or absent blood flow. There is no perivascular cellular infiltrate but obvious early destruction of collagen and adhesion of conjunctiva to the underlying tissue $(\times 180)$.

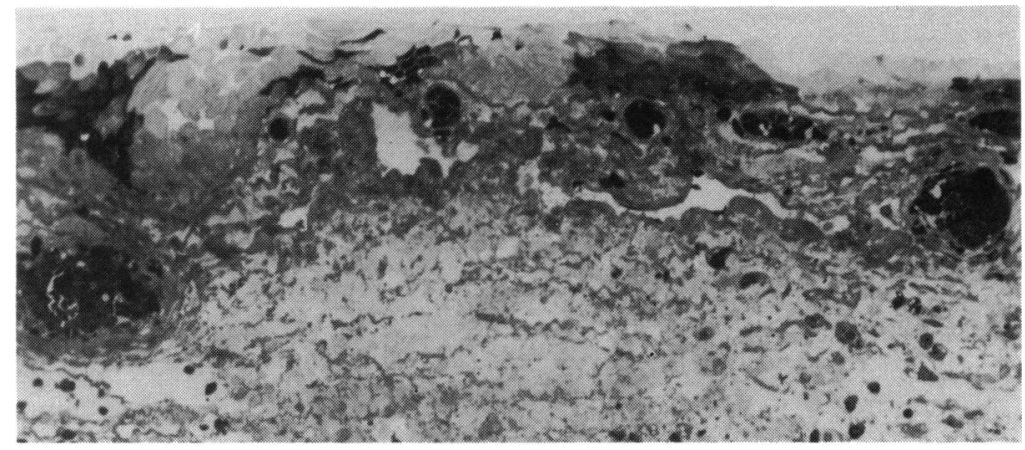

parable to that previously described at sites of scleral ulceration ${ }^{46}$ was detected in the tissue removed from the area studied by angiography. Although compromised vascular function was known to be present (Figs. 1-3), examination of the blood vessels at this site (Fig. 7) revealed that, although the vessels appeared patent, red cells were densely packed, consistent with sluggish or absent flow. There was no perivascular cellular infiltrate associated with these vessels.
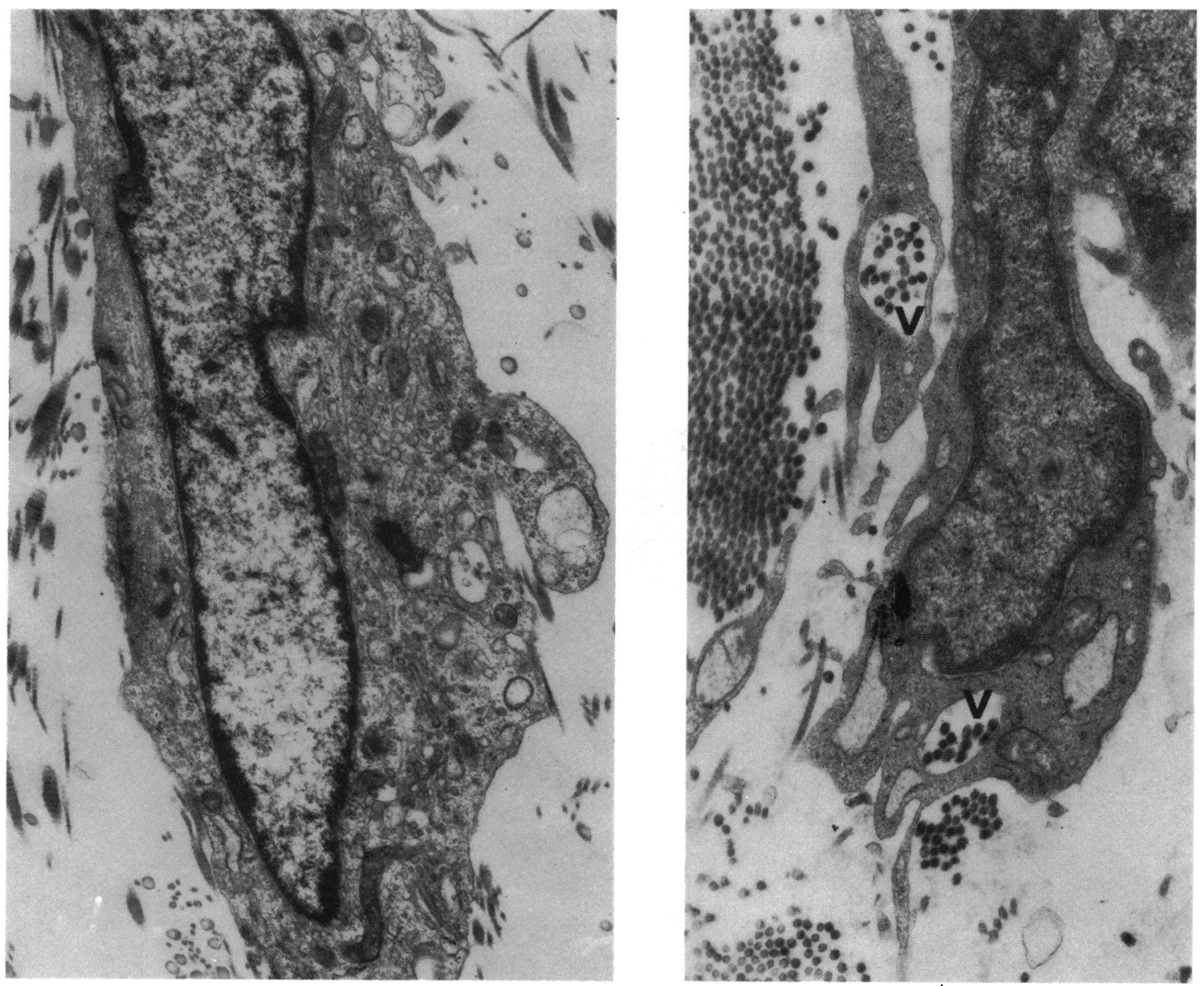

Fig. 8 Electron micrographs of scleral stroma at periphery of frank ulcer. Left shows active fibroblastic cell $(\times 15375)$. Right shows collagen fibrils within intracellular vacuoles $(v)$ in a fibroblastic cell $(\times 15375)$. 

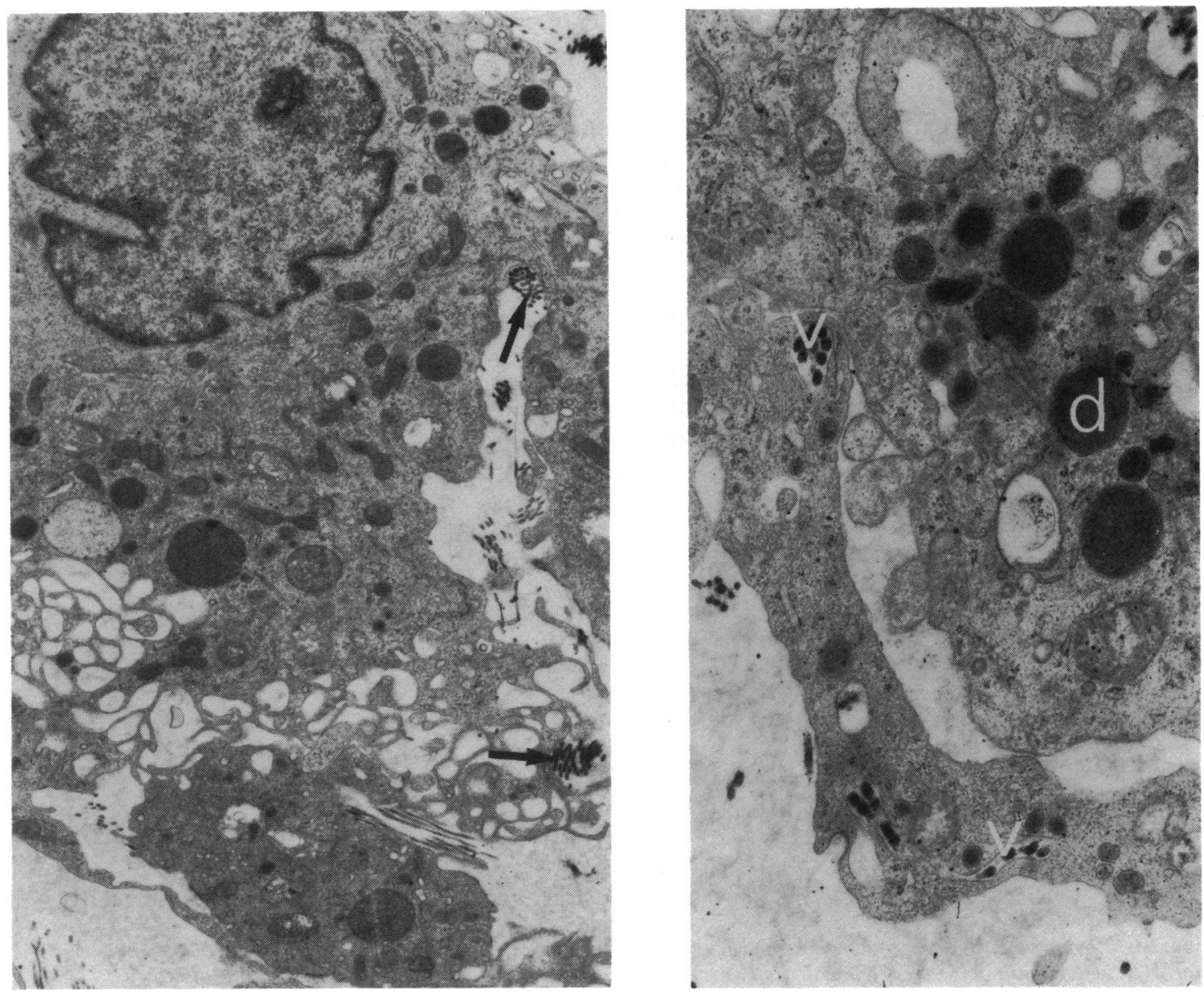

Fig. 9 Electron micrographs of scleral stroma at periphery of frank ulcer. Left shows macrophage-like cell with elaborate cell surface in close contact with collagen fibrils (arrows) $(\times 7145)$. Right shows collagen fibrils within vacuoles $(\mathrm{v})$ in a macrophage-like cell which also contains numerous dense granules $(d)(\times 15655)$.

The preliminary stages of matrix degradation in the conjunctiva and episclera were evident in this site, where there was no obvious demarcation between conjunctiva and episclera in the deeper tissues. The cellular element of the scleral connective tissue consisted of active-appearing fibroblastic cells and macrophage-like cells with elaborate cell surfaces and numerous cytoplasmic inclusions (Figs. 8 and 9, left). Both cell types were commonly observed with collagen fibrils or fibril fragments in close apposition with the cell membrane or pseudopodia, or partly or completely enclosed in membraneous folds and cytoplasmic vacuoles (Figs. 8 and 9, right). Dense cytoplasmic granules were frequently clustered within the macrophage-like cells in the vicinity of collagen fibril phagocytosis (Fig. 9, right).

In addition, degradative changes in collagen fibrils of the scleral matrix were apparently taking place without close apposition to active scleral cells. Collagen fibrils appeared to undergo swelling and unravelling (Fig. 10), which began at discrete sites and spread to involve extensive lengths of the fibril. In the outer sclera fibrils of large and small diameter appeared similarly affected.

No granulocytes or lymphocytes were found within these areas of matrix degradation.

\section{Discussion}

This is the first case in which the anterior segment angiographic appearances have been correlated with the pathological changes in necrotising scleral disease.

A constant angiographic feature of necrotising 


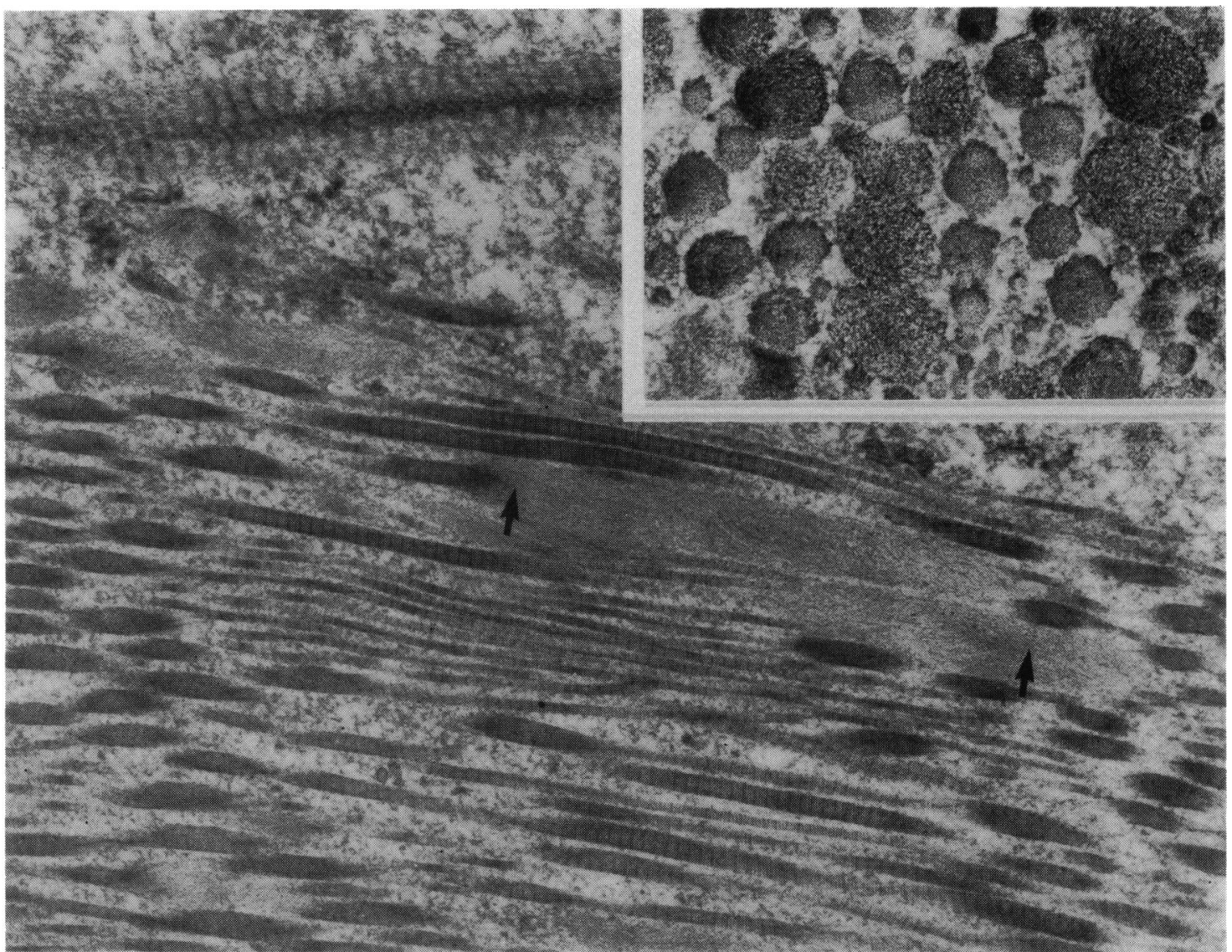

Fig. 10 Electron micrographs of scleral stroma at ulcer periphery showing swelling and unravelling of collagen fibrils (arrows) in longitudinal $(\times 29270)$, and in transverse section (inset, $\times 44000)$. Fibrils of all diameters are affected.

scleritis, whether tissue loss occurs or not, is that the rapid circulation through dilated normal vessels, which is part of the normal inflammatory response, gives way to sluggish and finally total absence of flow in vessels in the region of the necrotising process. When the inflammation has been suppressed by treatment, a few of the vessels near the the periphery of the lesion may become reperfused, but in many no flow can be detected, suggesting that the vessels have been thrombosed.

Either these non-perfused areas remain without any apparent circulation from the superficial vasculature, being traversed by large anastomotic vessels, or new capillaries extend into them either as solitary budding vessels or in the form of a fan, leaving a functional capillary bed behind.

In the case reported here the diagnosis of necrotising scleritis was obvious, but the extent of the necrotising process was not clear. Anterior segment fluorescein angiography precisely localised the extent of the vaso-obliterative process in one direction. (To have detected the extent below would have required a further angiogram in this instance because of deep leakage of fluorescein). At operation, although the site of the angiography was a considerable distance from the obviously abnormal tissue, the conjunctiva was found to be adherent to the underlying episclera and the texture of the underlying sclera and adjacent cornea abnormally soft.

Following surgery the interpretation of fluorescein angiograms is more difficult. However, in this case, when a recrudescence of the scleritis occurred, postoperative fluorescein angiography was of considerable value both as an indicator of renewed inflammatory disease which warranted further surgery and as an aid in the placement of the second graft. On the basis of information obtained from the angiogram the excision was extended into tissue peripheral to the new ulceration, which, while superficially of normal appearance, was shown by electron microscopy to be 
already involved in the degradative process. In view of the fact that a further inflammatory episode followed the second graft (which was readily treatable with short-term steroid) it is probable that the excision was not quite extensive enough.

Electron microscopy of tissue excised from sites of vascular closure peripheral to the scleral ulcer showed that, in contrast to the ulcer centre ${ }^{\text {th }}$ perivascular inflammatory cells were absent. However, on morphological criteria scleral stromal cells deep to these sites appeared highly active. Fibroblastic transformation of scleral cells throughout the full thickness of the stroma was associated with degradative changes in the matrix, often where the connective tissue appeared initially to be intact. Electron microscopy has shown' that in necrotising scleritis, as in other normal and pathological tissues ${ }^{8-10}$ where rapid resorption of connective tissue is evident, collagen degradation may take place via two routes: active engulfment of fibrillar material by phagocytic cells, which then degrade the protein via the lysosomal pathway, and by an extracellular mechanism, possibly involving release or activation in the matrix of collagenolytic enzymes from active fibroblasts.

This study indicates that scleral destruction in necrotising scleritis is already in progress at sites of vascular closure, which can be demonstrated by anterior segment fluorescein angiography, quite distant to the major granulomatous infiltration which occurs in this disease. As has been demonstrated here, if surgery has to be performed on these patients, the dissection must be extended into areas where the vascular pattern is normal.

This work was supported by grants from the Medical Research Council and the Wellcome Trust.

\section{References}

1 Watson PG, Hazleman BL. The sclera and systemic disorders. London: Saunders, 1976.

2 Watson PG. The nature and the treatment of scleral inflammation. Trans Ophthalmol Soc UK 1982; 102: 247-81.

3 Watson PG, Bovey E. Anterior segment fluorescein angiography in the diagnosis of scleral inflammation. Clin Ophthalmol in press.

4 Sevel D. Necrogranulomatous scleritis. Clinical and histological features. Am J Ophthalmol 1967; 64: 1125-34.

5 François J. Ocular manifestations in collagenoses. Adv Ophthalmol 1970; 23: 1-54.

6 Young RD, Watson PG. Microscopical studies of necrotising scleritis. I. Cellular aspects. Br J Ophthalmol 1984; 68: 770-80.

7 Young RD, Watson PG. Microscopical studies of necrotising scleritis II. Collagen degradation in the scleral stroma. $B r J$ Ophthalmol 1984; 68: 781-9.

8 Harris ED Jnr, Glauert AM, Murley AHG. Intracellular collagen fibres at the pannus-cartilage junction in rheumatoid arthritis. Arthritis Rheum 1977; 20: 657-65.

9 Padykula HA. Cellular mechanisms involved in cyclic stromal renewal of the uterus. Anat Rec 1976; 184: 49-71.

10 Van den Hoof A, Tigchelaar-Gutter W. Stromal changes in experimental carcinogenesis in the skin. I. Ultrastructural aspects of collagen degradation. Proc $K$ Nederlandse Akad Wetenschappen 1983; C86: 179-90. 